\title{
Contribuições histórico-culturais à Psicologia Escolar na Educação Especial Inclusiva
}

\author{
Historical-cultural contributions to School Psychology \\ in Inclusive Special Education
}

\author{
Sonia Mari Shima Barroco ${ }^{1}$ \\ Iracema Neno Cecilio Tada ${ }^{2}$
}

\begin{abstract}
RESUMO
Objetiva-se discutir as contribuições da Psicologia Escolar à Educação Especial sob a perspectiva da educação inclusiva à luz da Psicologia Histórico-Cultural (PHC). Aborda-se a Psicologia Escolar como área de atuação profissional que aplica estudos teórico-metodológicos e também os suscitam. Para o propósito, são apresentados aspectos conceituais sobre a educação escolar, o desenvolvimento do psiquismo, a educação especial e a inclusão. A Psicologia Escolar ao se pautar na tese central da PHC, a produção social do psiquismo, e ao recuperar os fundamentos teórico-metodológicos da defectologia vigotskiana, pode contribuir de modo efetivo no desvelamento e no enfrentamento das queixas escolares e na produção do fracasso escolar. Esta produção, não raramente, tem sido a porta de entrada para a Educação Especial, e nessa modalidade de ensino ela pode se instalar sob a sombra dos diagnósticos e laudos. Conclui-se que à Psicologia Escolar cabe manter-se numa perspectiva crítica, em defesa da boa escola, aquela que exerce a função clássica de ensinar e que busca estratégias adequadas para tanto, visto que todas as pessoas - com e sem deficiência podem aprender. Essa luta implica garantias de acesso à matrícula e à escola, de permanência com condições efetivas de acesso aos conteúdos científicos, artísticos, filosóficos, éticos e de convivência em
\end{abstract}

\begin{abstract}
The objective is to discuss the contributions of School Psychology to Special Education under the perspective of inclusive education in the light of Historical-Cultural Psychology (HCP). School Psychology is approached as an area of professional activity that applies theoreticalmethodological studies and also raises them. For the purpose, conceptual aspects about school education, the development of the psyche, special education and inclusion are presented. School Psychology, based on the central thesis of HPC, the social production of psyche, and recovering the theoreticalmethodological foundations of Vigotskian defectology, can effectively contribute to unveiling and confronting school complaints and the production of school failure. This production, not rarely, has been the gateway to Special Education, and in this teaching modality it can be installed under the shadow of diagnoses and reports. It is concluded that School Psychology must maintain a critical perspective, in defense of the good school, one that exercises the classic function of teaching and that seeks appropriate strategies for this, since all people - with and without disabilities - can learn. This struggle implies guarantees of access to enrollment and school, permanence with effective conditions of access to scientific, artistic, philosophical, ethical and coexistence contents in society, and completion of studies with appropriation and certification.
\end{abstract}

1 Programa de Pós-graduação em Psicologia - Universidade Estadual de Maringá, Brasil. ORCID: https://orcid.org/0000-0002-4136-8915. E-mail: smsbarroco@uem.br.

${ }^{2}$ Programa de Pós-Graduação em Psicologia - Universidade Federal de Rondônia, Brasil. ORCID. https://orcid.org/0000-0002-0081-953X. E-mail: iracema.neno@unir.br. 
sociedade, e de terminalidade dos estudos com apropriação e certificação.

Palavras-chave: Psicologia Histórico-Cultural. Educação Escolar. Desenvolvimento Humano.
Keywords: Historical-Cultural Psychology. Schooling. Human development.

\section{Introdução}

Abordar sobre a Psicologia Escolar requer uma delimitação clara, pois há tantos aspectos que podem ser contemplados e tantos enfoques possíveis, por ser uma das áreas mais antigas de formação e de atuação no âmbito da Psicologia, como já apontou Antunes (2008). Em concordância com a autora, com o presente texto objetiva-se discutir as contribuições da Psicologia Escolar à modalidade da Educação Especial sob a perspectiva da educação inclusiva, à luz da Psicologia Histórico-Cultural. Ele resulta de diferentes investigações científicas realizadas ou orientadas pelas autoras e de suas próprias atuações como psicólogas escolares, diante dos desafios postos na/pela Educação Básica. Esses desafios envolvem profissionais da educação, estudantes e famílias/comunidades e estimulam os estudos, à ascensão da prática sincrética e caótica em busca por respostas ou por elementos explicativos do real. O pensamento teórico aqui contemplado se apresenta como resultante dessa busca e instiga a que se volte ao real como concreto pensado - embora esse entendimento não seja aceito como consensual no próprio espaço escolar. Não raramente depara-se com professores, pedagogos, psicólogos entre outros profissionais afirmando que a teoria é uma coisa, a prática é outra, e que nessa é preciso fazer o que possa dar resultados, ou seja, aquilo que surta efeito.

É justamente contra entendimentos dicotômicos e anistóricos como esses que uma parcela significativa de profissionais e de estudiosos da Psicologia Escolar têm se posicionado. Assim, é importante que isso seja explicitado, visto que no Brasil prolifera o rechaço à teoria, a desqualificação da ciência de modo amplo e evidente. Vale lembrar que o 'recuo da teoria' já fora tratado por Moraes (2001) na entrada deste milênio, quando a autora chama a atenção para o momento de ressignificação de tudo, da teoria e das metanarrativas. Certo é que 
cada vez mais o exposto por Moraes (2001) ganha celeridade e robustez, sobretudo no Brasil, com os direcionamentos do atual governo federal de modo geral e no âmbito educacional, de modo específico.

Infelizmente na própria escola esse recuo pode ser observado, visto que nem sempre essa instituição cumpre com sua função clássica. E o que seria essa 'função'? Desde a Pedagogia Histórico-Crítica, que converge com a Psicologia Histórico-Cultural por adotarem a mesma matriz filosófica e metodológica do materialismo-histórico-dialético, tem-se essa resposta:

Ora, clássico na escola é a transmissão-assimilação do saber sistematizado. Este é o fim a atingir. É aí que cabe encontrar a fonte natural para elaborar os métodos e as formas de organização do conjunto das atividades da escola, isto é, do currículo. E aqui nós podemos recuperar o conceito abrangente de currículo: organização do conjunto das atividades nucleares distribuídas no espaço e tempo escolares. Um currículo é, pois, uma escola funcionando, quer dizer, uma escola desempenhando a função que lhe é própria. (SAVIANI, 2011, p.17)

Diante do exposto, é necessário que isso seja reafirmado, posto que a desqualificação da teoria se reflete no fato de que a escola sirva como espaço físico e social para tantas outras finalidades (ALVES, 2005), que não as atividades de ensino e de estudo, como espaço onde ou pelo qual se aprenda a pensar o real e a si mesmo, onde se desenvolva a consciência para além da imediaticidade empírica, onde o desenvolvimento do psiquismo é movimentado.

Isso se agrava ao se considerar o presente momento, quando, cada vez mais, adota-se a forma virtual de relação entre as pessoas e delas com os objetos, as coisas e a natureza, e o ensino remoto se apresenta como uma proposta cada vez mais 'plausível' para todas as séries e idades (!). Isso em muito preocupa, pois além de tudo o que já se apontou a respeito (SAVIANI; GALVÃO, 2020) preocupa o quanto isso favorece para que os conteúdos tenham mais chances de serem 'copiados' e 'colados' sem a necessária apropriação. É fundamental, portanto, que se tenha evidenciada a função clássica da escola, sob a pena de a Psicologia Escolar perder-se em sua 'função clássica'. E qual seria essa 'função'? 
A Psicologia Escolar deve atuar ou intervir com alunos, professores e demais profissionais, famílias ou responsáveis, gestores, comunidade externa etc., para que todas as pessoas que passam pela escola sejam metamorfoseadas ou revolucionadas (VYGOTSKY; LURIA, 1996) por aquilo que ela oportuniza, por aquilo que dela se apropriam. Nesse sentido, precisa identificar as múltiplas determinações que levam ao bom ensino, aquele que permite/favorece a aprendizagem e que movimenta o desenvolvimento, como apontou Vigotskii (2010) ao tratar da aprendizagem e do desenvolvimento intelectual na idade escolar.

No Brasil, a 'função clássica' da Psicologia Escolar é abordada em diferentes publicações, como a do Conselho Federal de Psicologia, Referências técnicas para atuação de psicólogas(os) na educação básica (2019). Nessa são apresentadas diferentes ações e estratégias de atuação desse profissional, apontando para a educação como direito fundamental. Em Referências, a educação é reconhecida como alvo de disputa - o que é compreensível, seja pelo orçamento que lhe é destinado, seja pelo que por ela é produzido, no campo das ideias e das práticas sociais. Daí a necessidade de a Psicologia voltar-se à educação, e, juntamente com profissionais de outras áreas afins, lutar por políticas públicas que garantam o cumprimento desse direito. Essa luta se acirra, e tem contribuído para o esgotamento e o adoecimento dos sujeitos implicados na medida em que se intensificam a desqualificação da escola e dos professores (FACCI; ESPER, 2021), a demanda por produção científica, por um lado, e os ataques à essa produção e à divulgação desse conhecimento pela precarização das condições ou pela sua explícita negação por outro. Embora possa não parecer evidente, está em curso a negação à acessibilidade e à apropriação dessa produção científica pela classe trabalhadora, em especial a mais pobre, cujas oportunidades de contato e de domínio desse saber ficam cada vez mais restritas.

A Psicologia Escolar deve estar, portanto, na defesa intransigente do direito à educação básica de qualidade para todas as pessoas com e sem deficiências ou necessidades educacionais especiais (NEE), ante o reconhecimento do papel que ela desempenha para constituição da 
genericidade em suas vidas. O empenho a ser continuado é, portanto, não somente pela garantia da vida (pela qual tanto se lutou em 2020 e 2021, em função da pandemia da Covid-19), mas pelo desenvolvimento das pessoas de todas as classes sociais, raças/etnias, credos etc., a patamares já alcançados pelo gênero humano. Esse posicionamento assume uma perspectiva crítica por não imputar às parcelas cada vez maiores da população as razões de ficarem à margem do processo de desenvolvimento, questionando o discurso meritocrático e capacitista que se fortalece com o recuo do pensamento teórico.

Por tal posicionamento, o profissional dessa área se destaca por reconhecer a transitoriedade ou a historicidade dos fenômenos aos quais é convocado a explicar e junto a eles intervir. Fazer valer o direito à vida e ao desenvolvimento, implica em se recuperar as gêneses e os processos constitutivos dos problemas que se lhes apresentam, estabelecendo relações de causalidade que nem sempre são compreensíveis à escola, à família, à sociedade, posto demandarem um cabedal teórico explicativo. E é esse cabedal que permite que se atravesse a camada da aparência da queixa escolar, ou do problema a ser enfrentado - aparência que, não raramente, é explicada pelo saber tácito, e tão naturalizada que engendra explicações da mesma ordem e intervenções não só equivocadas, mas perigosas, pelo que podem suscitar.

\section{Por uma perspectiva crítica}

Para fazer frente a isso, há algumas décadas se tornou possível identificar um conjunto de saberes acadêmico-científicos produzidos que toma a Psicologia Escolar como objeto de análise, e que vão compondo uma densidade teóricometodológica para sustentar esse campo de atuação ${ }^{3}$. No entanto, dentre tantos direcionamentos que os estudos desse campo de atuação profissional podem contemplar, é fundamental a superação de análises que tomam por individuais ou restritas a dados grupos, ou por biológicas e clínicas problemáticas que antes são de natureza estrutural, social e histórica. Exemplos dessas contribuições são

\footnotetext{
${ }^{3}$ No periódico Psicologia Escolar e Educacional são publicados regularmente estudos a respeito, e que contemplam um rol de especificidades, como consta em: https://www.scielo.br/j/pee/.
} 
as teorizações de Patto $(1983,1987,1990)$ sobre a produção do fracasso escolar, que pôs em questão índices alarmantes de reprovações nas séries iniciais. A autora discute se o fracasso escolar se deve aos problemas de deficiência [intelectual], de diferenças culturais entre outras, ou de trabalhos inconsistentes nas séries de alfabetização, revelando as fragilidades dos sistemas educacionais no país. As indagações seriam inexplicáveis pelos parâmetros usualmente empregados e que levam à individualização e à medicalização. Nessa linha crítica, Souza (1996) teoriza sobre a queixa escolar e a formação de psicólogos, e, Machado (1996) discute a avaliação psicológica.

Essas teorizações, entre outras, abriram frentes para que se tivesse um posicionamento crítico em Psicologia Escolar, não buscando o mero ajustamento dos sujeitos às concepções de normalidade e questionando o instituído nesse campo de atuação num momento emblemático de constituição da sociedade democrática no Brasil. Apontam, pois, para o caráter ético e político desse campo de atuação e das elaborações teóricas que ele suscitava e que o poderia nortear.

Estudos desse período das décadas de 1980 e 1990 contribuíram para a consolidação de uma perspectiva crítica e para a composição posterior de grupos no Brasil que passaram a adotar a Psicologia Histórico-Cultural como referencial teórico para subsidiar a prática (ASBAHR; SOUZA; BARROCO, 2021). Salienta-se que naqueles anos de saída da ditadura militar e de elaboração e implantação da Constituição Brasileira e da Lei de Diretrizes e Base da Educação Nacional - LDBEN 9.394/1996 (BRASIL, 1988; 1996) a Psicologia buscava por espaços nos quais pudesse fazer frente a toda forma de opressão e de discriminação das pessoas, delimitando, para tanto, objetos e metodologias de pesquisa. Sua inserção na Educação como campo profissional, e não apenas como disciplina que compõe os fundamentos da educação - a Psicologia Educacional - carrega essas marcas.

Com a LDBEN, a indagação sobre qual a contribuição da Psicologia Escolar na modalidade da Educação Especial, que atravessa os níveis da Educação Básica em suas etapas (Educação Infantil, Ensino Fundamental Anos Iniciais e Anos 
Finais, e, Ensino Médio) e o Ensino Superior (Graduação e Pós-graduação), e as demais modalidades de ensino, tem estado na pauta das discussões.

Passados 25 anos da promulgação da LDBEN, e com a aprovação de diferentes leis e documentos regulamentando a Educação Especial sob a perspectiva da inclusão, e, mais recentemente, da Lei 13.925/2019 (BRASIL, 2019), que dispõe sobre os profissionais de Psicologia e do Serviço Social para comporem as equipes multidisciplinares de profissionais da educação nas redes públicas de ensino, o debate sobre essas contribuições têm se intensificado visando a garantia de boas escolas públicas. Para tanto, se faz mister que o psicólogo escolar e educacional identifique e analise as contradições estruturais da sociedade contemporânea, as políticas públicas para a educação, as tensões institucionais existentes, que se constituem em múltiplas determinações para se constituir a queixa escolar, superando a prática de se abordar o estudante descolado desse contexto.

A Psicologia Escolar contribui para tanto atentando-se às queixas, como: evasão escolar, violência nas escolas, adoecimento de professores e de alunos, racismo contra o negro, o indígena etc., discriminação de gênero, de orientação sexual, de pobreza e de crença. Essas questões se apresentam em meio às dificuldades relacionadas ao ensino e à aprendizagem, à precariedade na formação teórico-metodológica dos professores e de demais profissionais, à falta de condições adequadas para o trabalho educativo, às dificuldades de se chegar e permanecer na escola com segurança e dignidade, ao problema da insuficiência do número de profissionais, ao plano de carreira dos professores com salários baixos e defasados etc.

Tudo isso se torna ainda mais preocupante posto que se agudizar na situação de exceção provocado pela Pandemia da Covid-19 e pela ausência de uma política nacional condizente à valorização da vida, da saúde e da educação para enfrentá-la. Nesse sentido, quando se pensa nessas problemáticas atingindo o público-alvo da Educação Especial, que requer múltiplas adequações/adaptações para o ensino e a efetiva aprendizagem, a preocupação aumenta. Expor, pois, sobre as contribuições da Psicologia Escolar à Educação Especial e Inclusiva, 
requer que se pense sobre as suas atribuições e que se teçam considerações sobre a Educação Especial Inclusiva e a escola que se pleiteia.

\section{Psicologia Escolar: campo profissional orientado pela ciência}

A vinculação da Psicologia à Educação tem sido alvo de interesse de diferentes estudos acadêmico-científicos, como aponta Schlindwein (2010). Identificar as demandas contextuais e históricas para a constituição da subárea do conhecimento denominada Psicologia da Educação, e da Psicologia Escolar como campo profissional no qual o saber científico sobre ensino, aprendizagem e desenvolvimento humano deve estar implicados, permite que se identifique e se reconheça o papel da educação na constituição dos sujeitos ou na sua humanização.

Segundo Antunes (2008, p. 470),

A Psicologia Educacional pode ser considerada como uma sub-área [sic] da psicologia, o que pressupõe esta última como área de conhecimento. Entende-se área de conhecimento como corpus sistemático e organizado de saberes produzidos de acordo com procedimentos definidos, referentes a determinados fenômenos ou conjunto de fenômenos constituintes da realidade, fundamentado em concepções ontológicas, epistemológicas, metodológicas e éticas determinadas.

Antunes (2008, p. 470) a diferencia da Psicologia Escolar, que se caracteriza pelo âmbito profissional e diz respeito

[...] a um campo de ação determinado, isto é, o processo de escolarização, tendo por objeto a escola e as relações que aí se estabelecem; fundamenta sua atuação nos conhecimentos produzidos pela psicologia da educação, por outras sub-áreas [sic] da psicologia e por outras áreas de conhecimento. Deve-se, pois, sublinhar que psicologia educacional e psicologia escolar são intrinsecamente relacionadas, mas não são idênticas, nem podem reduzir-se uma à outra, guardando cada qual sua autonomia relativa.

Ambas, podem abarcar "[...] uma diversidade de concepções, abordagens e sistemas teóricos que compõem o conhecimento, particularmente no âmbito das ciências humanas, das quais a psicologia faz parte” (ANTUNES, 2008, p. 470). A 
Psicologia da Educação compõe as disciplinas de Fundamentos da Educação que formam também professores e pedagogos.

Assim, o que essa disciplina ensina e como o faz é de interesse quando se pretende uma perspectiva crítica na escola. Cabe considerar que desde os primórdios da Psicologia como ciência e profissão ${ }^{4}$, a vinculação e a atuação do Psicólogo à Educação Especial pautavam-se muito em práticas psicométricas, com foco nos aspectos evolutivo-maturacionais do desenvolvimento humano - algo que ainda se mantém.

Ocorre que essa forma de atuação, subsidiada historicamente por teorias psicológicas do desenvolvimento humano de base idealista e positivista, restringe a compreensão a respeito da aprendizagem e do desenvolvimento do aluno que não acompanha a contento o ritmo da turma ou dos colegas com idades próximas. A prática da comparação se dá com o instituto da normalidade, que em geral se pauta na prevalência de dadas condutas consideradas desejáveis ou aceitáveis para dados grupos sociais, e em determinadas fases da vida. Nesse sentido, é bem comum, com apoio dessas teorias, não se levar em conta os diferentes fatores que incidem sobre a sua vida escolar, ou não reconhecer que eles existam, e, assim, não se apresentar medidas ou programas escolares e extraescolares para fazer frente às necessidades e demandas que vão se apresentando.

Em parte, é mais simples e cômodo que psicólogos, professores, pedagogos encontrem as justificativas ou respostas no corpo do aluno do qual se queixa (numa prática de biologização), em suas condutas e nas relações familiares instituídas (sob o viés da moralidade) para as suas dificuldades de aprendizagem e para o seu insucesso escolar. Essa prática de individualizar no sujeito, em sua família ou nos grupos socioeconômico e/ou étnico-racial aos quais pertence, problemáticas que antes são estruturais, descarta a mediação do pensamento e a posterior contestação sistemática e consistente, acabando por se naturalizar. Um posicionamento contrário torna-se trabalhoso;

\footnotetext{
${ }^{4}$ A Lei $\mathrm{N}^{\circ} 4.119$, de 27 de agosto de 1962, dispõe sobre os cursos de formação em psicologia e regulamenta a profissão de psicólogo.
} 
demanda o estranhamento atento, responsável e propositivo, enfrentando a negação reiterada das análises e dos consequentes redirecionamentos nas rotinas escolares e da vida em geral que elas possam suscitar.

A atuação da Psicologia Escolar deve se respaldar, pois, na ciência, e aqui se entende a ciência como um conjunto de saberes sistematizados que podem ser comprovados e que transpassam as aparências dos fenômenos ou objetos que se visa conhecer; que desvela as relações existentes entre eles, mas que não se mostram imediata e obviamente articuladas. A ciência deve revelar as suas gêneses, os seus processos constitutivos, os seus movimentos e as suas contradições. O saber científico deve ser transformado em saber escolar, e explicar o porquê isso não ocorre, ou o porquê desse saber não provocar o aluno, deve ser alvo da atenção da Psicologia Escolar. Como escreve Saviani (2011, p. 201): “[...] o papel da escola não é mostrar a face visível da lua, isto é, reiterar o cotidiano, mas mostrar a sua face oculta, ou seja, revelar os aspectos essenciais das relações sociais que se ocultam sob os fenômenos que se mostram a nossa percepção imediata."

Nessa mesma direção, Luria (1996) escreveu: "V. I. Lenin ressaltou que o objeto de conhecimento, e em consequência, objeto da ciência não são as coisas em si, mas principalmente a relação entre elas" (p.11). A psicologia como ciência, conforme Rubinshtein (1961, p. 13, tradução nossa) “[...] é a ciência dos fenômenos psíquicos, ou seja, das funções cerebrais que refletem a realidade objetiva". Rubinshtein (1961, p. 13, grifo no original, trad. nossa) ${ }^{5}$ explica que

Os fenômenos psíquicos, sensações e percepções, representações e pensamentos, sentimentos e desejos, necessidades e interesses, inclinações e capacidades, qualidades volitivas e traços de caráter, nos são tão familiares que a simples vista parece que os conhecemos bem. No entanto, a concepção científica e verdadeira desses fenômenos constitui um dos grandes problemas da ciência.

\footnotetext{
5 "Los fenómenos psíquicos, sensaciones y percepciones, representaciones y pensamientos, sentimientos y deseos, necesidades y intereses, inclinaciones y capacidades, cualidades volitivas y rasgos de carácter, nos son tan familiares que a simple vista parece que los conocemos bien. Sin embargo, la concepción científica y verdadera de estos fenómenos constituí uno de los grandes problemas de la ciencia”.
} 
Analisa que

O objeto principal da Psicologia é o estudo das leis que regem as funções psíquicas e seu desenvolvimento, ou seja, conhecer como se forma e se aperfeiçoa a imagem reflexa do mundo objetivo no cérebro do homem, como este desenvolve sua atividade de acordo com ela e como se formam os traços psíquicos da personalidade. (RUBINSHTEIN, 1961, p. 13, grifo no original, trad. nossa) ${ }^{6}$

Ao tratar das funções psíquicas isso não significa que o autor propõe uma imersão no cérebro, mas sim que, considera que a "[...] psiquê ou a consciência humana reflete a realidade objetiva, o estudo das leis psicológicas significa, em primeiro lugar, estabelecer a dependência dos fenômenos psíquicos a respeito das condições objetivas da vida e da atividade do homem” (RUBINSHTEIN, 1961, p. 24, grifo no original, trad. nossa).

Essa atividade humana que permite ao homem viver e reproduzir-se como gênero humano em conformidade com os espaços temporal, geográfico, cultural e socioeconômico pode estar vinculada ao trabalho ou ao processo produtivo, à escolarização etc. Essa compreensão, de que é por ela que garante a vida em seu aspecto biológico e humano genérico, é da maior importância, pois abre à Psicologia Escolar uma gama de possibilidades de teorizações e de intervenções, em favor do desenvolvimento de todos os sujeitos implicados. Daí a defesa intransigente da boa escola para todas as pessoas, visto que nela se transmite às novas gerações os saberes elaborados, instrumentalizando-as para terem uma relação cada vez mais indireta e complexa com seus pares e com o mundo, mediatizadas pelo pensamento.

\section{Psicologia Escolar e a luta pela boa escola}

Esses aspectos teóricos expostos abrem à Psicologia Escolar a possibilidade de entender que a Educação Especial na perspectiva inclusiva, tão defendida por estudiosos, professores, gestores e outros profissionais da educação desde a

\footnotetext{
6 "El objeto principal de la Psicología es el estudio de las leyes que rigen las funciones psíquicas y su desarrollo, o sea, conocer cómo se forma y perfecciona la imagen reflexa del mundo objetivo en el cerebro del hombre, cómo éste desarrolla su actividad de acuerdo con ella y cómo se forman los rasgos psíquicos de la personalidad.”
} 
Declaração de Salamanca (UNESCO, 1994), não se limita ao aceite de matrículas do público-alvo da Educação Especial (pessoas com deficiências, transtorno do espectro autista - TEA, superdotação/altas habilidades) em escolas comuns. Antes, diz respeito à educação que faz frente a toda sorte de desigualdades e de distanciamentos impostos pela organização da vida societária sob o capitalismo cuja lógica central está justamente na produção da diferença, pela liberdade de acumulação privada da riqueza material e não material que se produz socialmente. Se a citada Declaração foi fundamental para que a educação e a sociedade em geral pudessem rever suas práticas de discriminação de promoção de desigualdades e de preconceitos, após quase três décadas de sua elaboração há que se avaliar os alcances obtidos.

Barroco (2018) expõe que na década de 1990 a proposição da educação na perspectiva da inclusão escolar expressa as contradições daquele momento. Nele se deu o fim do comunismo real na Alemanha e na União Soviética, o que pôs em questão a possibilidade de uma sociedade mais igualitária. Naquele contexto caberia à sociedade capitalista lidar com as contradições que se avolumavam, e, a Declaração, embora não enfrente as raízes das desigualdades, chama a atenção para outros modos de se pensar a educação e a própria vida, com reconhecimento das diferenças como parte do existir humano.

Sob inspiração da Declaração, entre outros documentos como a Declaração de Jomtiem (UNESCO, 1990), muito se conquistou no Brasil em relação às matrículas do público-alvo da Educação Especial. Em 2020 tinha-se 47,3 milhões de matrículas na Educação Básica, sendo que 1,3 milhão era de alunos com deficiência, transtornos globais do desenvolvimento (aqui se inserem as pessoas com TEA) e/ou altas habilidades/superdotação em classes comuns incluídos ou em classes especiais exclusivas (INEP, 2020).

Todavia, ainda há muito por se fazer, diante dos retrocessos que a educação vem sofrendo, com destaque para o Decreto $\mathrm{N}^{\circ} 10.502$, de 30 de setembro de 20207, que institui a Política Nacional de Educação Especial:

\footnotetext{
${ }^{7}$ Disponível em https://www.cartacapital.com.br/diversidade/toffoli-revoga-decreto-de-bolsonarosobre-politica-de-educacao-especial/. Acesso em 03 nov. 2021.
} 
Equitativa, Inclusiva e com Aprendizado ao Longo da Vida, assinado pelo Presidente Jair M. Bolsonaro, sem partido, revogado por Dias Toffoli, ministro do Supremo Tribunal Federal, por dar margem para "[...] fundamentar políticas públicas que fragilizam o imperativo da inclusão de alunos com deficiência, transtornos globais do desenvolvimento e altas habilidades ou superdotação na rede regular de ensino".

Destarte, ao se pensar na ideia de educação inclusiva que se expôs, para que se alargue o acesso à apropriação do conhecimento, sem a qual fica comprometido o processo de objetivação. Esse duplo processo de apropriação e de objetivação é que permite aos alunos constituírem-se como singulares.

Leontiev (1978) teoriza que ao longo da sua história os conhecimentos adquiridos durante o desenvolvimento das faculdades e propriedades humanas acumularam-se, fixaram-se não pelas particularidades morfológicas transmitidas hereditariamente, mas, pelas leis sociais foram transmitidos de geração em geração. Pela atividade do trabalho o homem tem garantido a sua existência, alterando a natureza e a si mesmo. Destaca que há um

[...] processo de encarnação, de objetivação nos produtos das atividades dos homens, das suas forças e faculdades intelectuais e a história da cultura material e intelectual da humanidade manifesta-se como processo, que exprime, sob uma forma exterior e objetiva, as aquisições do desenvolvimento das aptidões do gênero humano. (LEONTIEV, 1978, p. 177)

Nas criações do homem fica fixado o seu próprio desenvolvimento, e ao ser compartilhado com as novas gerações elas se apropriam do conjunto das faculdades ali contidas. Leontiev (1978, p. 178) explica que

No decurso do seu desenvolvimento ontogênico o homem entra em relações particulares, específicas, com o mundo que o cerca, mundo feito de objetos e de fenômenos criados pelas gerações humanas anteriores. Esta especificidade é antes de tudo determinada pela natureza desses objetos e fenômenos. Por outro lado, é determinada pelas condições em que se instauram as relações em questão.

Esclarece ainda que 
O mundo real, imediato, do homem, que mais do que tudo determina a sua vida, é um mundo transformado e criado pela atividade humana. Todavia, ele não é dado imediatamente ao indivíduo, enquanto mundo de objetos sociais, de objetos encarnando aptidões humanas formadas no decurso do desenvolvimento da prática-sócio-histórica; enquanto tal, apresenta-se a cada indivíduo como problema a resolver. (LEONTIEV, 1978, p. 178).

Conforme Leontiev (1978, p.180), o resultado do processo de assimilação ou apropriação "[...] é a reprodução pelo indivíduo, das aptidões e funções humanas, historicamente formadas”, ou ainda, “[...] é o processo pelo qual o homem atinge no seu desenvolvimento o que é atingido, no animal, pela hereditariedade, isto é, encarnação nas propriedades do indivíduo das aquisições do desenvolvimento da espécie”.

Leontiev (1978, p.181) explica que

As aptidões e funções formadas no homem no decurso deste processo são neoformações psicológicas, relativamente às quais os mecanismos e os processos hereditários, inatos, não passam de condições interiores (subjetivas) necessárias que tornam o seu aparecimento possível. Em nenhum caso determinam a sua composição ou a sua qualidade específica.

Isso em muito importa, pois, sob essa perspectiva, apropriar-se de um objeto não se limita a descrevê-lo em suas características e propriedades, mas incorporá-lo como instrumento de operações físicas ou mentais de modo próprio aos propósitos que se tenha. Assim, a apropriação da cultura historicamente construída, e transformada em saber escolar, é fundamental para o desenvolvimento dos alunos com e sem deficiências ou NEE, para a internalização da experiência social, para a formação da genericidade.

A objetivação, por sua vez, diz respeito à materialização das atividades físicas e mentais do homem naquilo que cria. Ou seja, a objetivação se dá quando a atividade física e/ou mental do homem se transfere, fixa-se no processo e no produto gerado. Nesse sentido, é possível dizer que a atividade humana é transferida para o produto da atividade, é nele encarnada e objetivada. 
A escola precisa estar atenta e promover essa dialética entre apropriação e objetivação. Para tanto, o aluno deve apropriar-se de um objeto ou fenômeno, precisa dominar a atividade correspondente nele fixada. Quando isso se dá, quando o aluno se apropria de um instrumento material ou simbólico significa que nele se formaram ações e operações motoras e mentais essenciais para o seu uso ou manejo. Esse instrumento deixa de ser algo externo e para ser algo seu, que serve mediar sua atividade física ou mental.

Por esse duplo processo, de apropriação e de objetivação, o aluno vai se humanizando, vai desenvolvendo características propriamente humanas, à medida que vai se apropriando dos resultados da história social também elabora novas objetivações, estabelecendo um movimento infinito com seus pares e o mundo. A boa escola, aquela que se adianta ao desenvolvimento, é também aquela que potencializa esse duplo processo, de modo a superar todas as formas de impedimentos, de barreiras interpostas entre os alunos e as elaborações humanas. Dito de outro modo, a escola inclusiva é aquela que se empenha para que todas as pessoas possam se apropriar das riquezas materiais e não materiais que a humanidade criou. A escola inclusiva é aquela na qual o próprio professor não é excluído, não se vê alienado do seu ofício, o ensino, e das ferramentas, o conhecimento.

No entanto, a Psicologia Escolar precisa estar ciente de que esse duplo processo está na berlinda e que isso trará, certamente, consequências duríssimas para grande parcela da população que depende da escola, dela exercer a sua função clássica para que se desenvolvam. O não enfrentamento rápido, de modo científico e amplo, do não ensino a contento trará, a uma grande parcela de crianças brasileiras, um resultado nefasto.

Isso em muito importa, pois,

Como toda ciência, a psicologia serve para transformar e melhorar a vida. A psicologia tem uma aplicação imediata na educação. Ao estudar as leis dos fenômenos psíquicos descobre os meios e métodos para desenvolver as funções psíquicas do homem e os traços de sua personalidade. Daí que a primeira e principal 
aplicação prática da psicologia seja em educação e no ensino das jovens gerações. (RUBINSHTEIN, 1961, p. 26, trad. nossa) ${ }^{8}$

Para tanto, requer que se exercite na apreensão dos fenômenos em suas causalidades, em seu desenvolvimento e desdobramentos.

\section{Psicologia Escolar e a Educação Muito Especial}

O posicionamento de Rubinshtein no tocante à Psicologia como ciência, seu objeto e sua vocação em busca de melhoria da vida, aliado à teorização de Vygotski (1997) sobre os fundamentos teórico-metodológicos para uma nova defectologia, ajuda a pensar a Psicologia Escolar em sua atuação junto à Educação Especial na perspectiva inclusiva.

$\mathrm{O}$ primeiro ponto a se destacar é a concepção de não fatalidade. $\mathrm{Ou}$ seja, Vygotski escreve que a deficiência não seria necessariamente uma desventura, ela se torna dessa forma ante as condições sócio-históricas. Antes, contraditoriamente, pode ser mola propulsora para o desenvolvimento, afinal, “'Aquilo que não mata, me faz mais forte', implicando que a força surge da debilidade, as atitudes das deficiências (W' Stern, 1923, pág. 145 [sic])" (VYGOTSKI, 1997, p. 41, trad. nossa) ${ }^{9}$. Essa concepção reflete a tese da formação social do psiquismo, o que implica em edificar sobre o equipamento biológico (complicado pela deficiência) o edifício cultural, ocupando a educação escolar um papel fundamental nessa edificação. Para Vygotski (1997), quanto mais se vencer a natureza antissocial da escola especial, quanto menos se isolar e segregar as pessoas com deficiência, quanto antes a incluir na vida comum daqueles que não têm a mesma condição, mais se favorece o desenvolvimento delas, mais as edificações culturais podem se realizar. Escreve que

\footnotetext{
${ }^{8}$ Como toda ciencia, la psicología sirve para transformar y mejorar la vida. A psicología tiene una aplicación inmediata en la educación. Al estudiar las leyes de los fenómenos psíquicos descubre los medios y métodos para desarrollar las funciones psíquicas del hombre y los rasgos de su personalidad. De aquí que la primera y principal aplicación práctica de la psicología sea en educación y enseñanza de las jóvenes generaciones. (RUBINSHTEIN, 1961, p. 26).

9 “'Aquello que no mata, me hace más fuerte', implicando que la fuerza surge de la debilidad, las aptitudes de las deficiencias' (W Stern, 1923, pag. 145)”.
} 
[...] como princípio, deve ser criado o sistema combinado de educação especial e comum que propõe Scherbina. A fim de vencer a antissociabilidade da escola especial, é preciso realizar um experimento cientificamente fundamentado de ensino e educação compartilhada entre cegos e videntes, experiência que tem um imenso futuro. $O$ âmbito do desenvolvimento tem aqui um curso dialético: primeiro, a tese da instrução comum de crianças anormais e normais; depois, a antittese, isto é, a instrução especial. A tarefa de nossa época é criar a sintese, isto é, a instrução especial, reunindo em uma unidade superior os elementos válidos da tese e da antítese. (VYGOTSKI, 1997, p. 85, trad. nossa, grifos nossos) ${ }^{10}$

Entende-se que a Psicologia Escolar tem diante de si o desafio de contribuir com essa síntese apontada por Vygotski, em texto de 1924, abordando sobre as pessoas cegas, mas que cabe ao público-alvo da Educação Especial como um todo.

Como levar esse público, tão diverso, à aprendizagem e, com isso, ao desenvolvimento de seu psiquismo? A Psicologia Escolar, diante dessa questão não deve ter como foco apenas o estabelecimento de habilidades sociais necessárias para o convívio social, mas o desenvolvimento das funções psicológicas superiores em patamares cada vez mais complexos, às quais essas habilidades devem se vincular. Avançar dos propósitos de treinamentos e condicionamentos para o de desenvolvimento dessas funções que são orientadas pela consciência e pela volição se apresenta como norte do seu trabalho. Nele, deve se atentar, além dos quadros específicos das deficiências ou NEE, às particularidades das diferentes idades e periodização, às significativas mudanças da atividade psíquica, nos diferentes períodos da vida e nas múltiplas determinações implicadas (BARROCO; LEONARDO, 2020). Embora as leis do desenvolvimento filogenético não se repitam no plano ontogenético, identificar a gênese e o desenvolvimento das funções psicológicas básicas e superiores, considerando ambas as linhas do desenvolvimento humano permitem o

\footnotetext{
10 “[...] como principio, debe ser creado el sistema combinado de educación especial y com ún que propone Scherbina. A fin de vencer la antisociabilidad de la escuela especial, es preciso realizar un experimento científicamente fundamentado de enseñanza y educación compartida entre ciegos y videntes, experiencia que tiene un inmenso futuro. El á mbito del desarrollo tiene aquí un curso dialectico: primero, la tesis de la instrucción común de niños anormales y normales; después, la antítesis, es decir, la instrucción especial. La tarea de nuestra época es crear la síntesis, es decir, la instrucción especial, reuniendo en una unidad superior los elementos validos de la tesis y la antítesis."
} 
reconhecimento da historicidade das mesmas e suas vinculações ao modo como se dá a produção e reprodução da vida, e o desenvolvimento do psiquismo. Isso permite à Psicologia Escolar investigar e intervir sobre as atividades principais ou guias (de brincar, estudar) (LEONTIEV, 2010) que orientam a vida cotidiana dos alunos e seus desenvolvimentos.

Pelo exposto, esses direcionamentos dados ao exercício da Psicologia Escolar, entre outros, permite que se desmascare a superioridade genética de uma raça sobre outra, de um grupo sobre outro, e toda elocubração de matriz eugênica e/ou higienista forjada no bojo da sociedade capitalista, que a despeito de alardear princípios democráticos, promove a exclusão daqueles que fogem às normas que se tornam prevalentes ou hegemônicas, que tanto pode seduzir os profissionais da educação, dentre eles os próprios psicólogos, os alunos e suas famílias e a sociedade em geral. Não se trata de tarefa fácil, visto demandar investimentos de diferentes naturezas para se criar vias alternativas, vias colaterais de desenvolvimento em sociedades preparadas justamente para dadas formas de reprodução da vida - que contam com o emprego da visão, da audição, da linguagem verbal oralizada e escrita, da desenvoltura psicomotora e da capacidade de compreensão das relações dos homens entre si e com o mundo para além do intelecto prático.

Como escreveu Vygotski (1997) no começo do século XX, tudo está preparado para um tipo normal de pessoa. De lá para cá, obviamente que muito se alterou, com políticas públicas voltadas para o público-alvo da Educação Especial, com a criação de próteses, órteses, procedimentos e processos, aplicativos etc. que permitem reconhecer que o normal abrange a deficiência, a diferença e a diversidade. O anormal é que toda essa criação não esteja acessível àqueles que dela demandam, como tão bem explicitado no Estatuto da Pessoa com Deficiência - Lei n ${ }^{\circ}$ 13.146, de 6 de julho de 2015 (BRASIL, 2015).

\section{Psicologia Escolar e a porta de entrada na Educação Especial}

Tendo por base epistemológica e metodológica o preconizado pela Psicologia Histórico-Cultural, pode-se dizer que após um século dos estudos iniciais de L. S. 
Vigotski (1896-1934) que deram início a essa escola psicológica, a tese central da formação social do psiquismo é muito propalada, mas, de fato, ainda incipiente no campo educacional em geral, e de modo específico na Educação Especial.

Após vários textos de Vigotski, de seus colaboradores e continuadores contemporâneos terem sido divulgados nas últimas décadas, expondo como essa tese pode ser comprovada em diferentes subáreas da Psicologia e da Educação, a concepção de aluno ideal ainda permeia o trabalho educativo, o que pode levar a práticas educacionais que pouco promovem o desenvolvimento. Esse ideal é tão presente que, por exemplo, é comum se pensar que pessoas com síndrome de Down sejam sempre gentis e amigáveis, que pessoas com autismo não sejam afetivas, que pessoas inquietas tenham transtornos etc.

O não domínio teórico a respeito do ensino ou da instrução, da aprendizagem e do desenvolvimento, como já se poderia dominar, contribui para que se tenha presente a hipótese de que há deficiência intelectual, transtorno do espectro autista, ou quadros de "dis" (dislalia, dislexia, discalculia, disgrafia) quando as queixas escolares sobre os alunos com dificuldades de aprendizagem são apresentadas. Sob essa hipótese, torna-se naturalizada a prática de os avaliar com testes formais, para se produzir diagnósticos e laudos - isso gerou até uma expressão usual nas escolas: o aluno laudado.

Não que a avaliação formal seja desnecessária, pelo contrário, ela é condição para que o aluno participe de programas e de serviços próprios da modalidade de Educação Especial na perspectiva da inclusão. No entanto, os propósitos dela deveriam evidenciar, tanto quanto possível, os frutos e os brotos do desenvolvimento, as crises e as metamorfoses em curso (VYGOTSKY; LURIA, 1996) - afinal é na zona de desenvolvimento proximal que o ensino para alunos com e sem deficiência deve atuar, trazendo à tona e formando camadas e camadas de potencialidade (VYGOTSKI,1996; 1997; 2000).

A atuação da Psicologia Escolar junto à Educação Especial começa com indagações: por que o aluno não aprende como os demais, por que não domina o saber escolar como os demais? Elas encaminham para a investigação, para a determinação de estratégias que visem explicitar a gênese e o processo desse 
problema. Isso demanda atenção ao desenvolvimento das funções psicológicas superiores, bem como às determinações da personalidade e do meio que os favorecem ou os obstaculizam (a gênese e o processo).

Os dados que produzem e suas análises derivam em encaminhamentos de trabalhos de formação e/ou de apoio aos profissionais da escola e/ou de intervenções com o aluno, que podem gerar resultados relevantes, tornando as intervenções sistematizadas passíveis de serem generalizáveis aos demais alunos da turma ou àqueles com queixas semelhantes.

Contudo, o processo de se avaliar e de se acompanhar formalmente o aluno alvo de queixa escolar, com emprego de protocolos para levantamento de informações e de produção de dados sobre as áreas intelectual, afetiva e social pode se dar de modo pouco articulado - algo recorrente quando não se tem uma teoria que subsidie o pensamento científico na atuação profissional. Esse pensamento teórico é que lhe possibilita sustentar a indivisibilidade afetivocognitiva do ser humano, e, portanto, do aluno; de evidenciar o papel fundante do ensino escolar sobre o desenvolvimento do seu psiquismo e da sua personalidade. Além disso, quando as condições socioeconômicas, ou os impactos da classe social à qual o aluno pertença não são efetivamente consideradas, pode se ter uma compreensão pouco elucidativa sobre a queixa escolar; ou ainda, pode ser elaborada uma compreensão enviesada a respeito, como, reiterando que os alunos de dada escola sejam fracos, oriundos de famílias tidas como desestruturadas e sem interesse em estudar, com dificuldades sociais insuperáveis etc. Concepções como essas direcionam para tornar patológico o que é histórico-cultural: a não presença, de fato, da atividade de ensino, da atividade de estudo e, por conseguinte, da aprendizagem dos conteúdos curriculares.

$\mathrm{Na}$ cotidianidade do trabalho escolar infelizmente pode ser desconsiderado que aquilo que a humanidade produz deveria, após uma seleção lógica e graduada com vistas às finalidades educacionais, tornar-se conteúdo curricular e que as apropriações dessas produções se dão em meio a imbricadas relações estabelecidas entre o aluno, a escola, a família, e, a sociedade (FACCI; TADA, 2012; ROSSATO; LEONARDO, 2012). Quando essas apropriações não se dão 
como se poderia esperar em conformidade com o preconizado pela LDBEN, com políticas públicas educacionais específicas e com os sistemas educacionais, por diferentes causalidades, instala-se um campo fecundo para a criação de rótulos que perpetuam o estigma social e afetam negativamente a escolarização.

À luz da teoria vigotskiana, pode se considerar que por detrás desse quadro de insucesso na escolarização está, sim, a perpetuação da ideologia dominante, a ideia de menos valia daqueles que não têm as condições efetivas de fruir do que a humanidade tem produzido. A vida cotidiana já torna uma parcela significativa de alunos alijada de conhecer, de fruir e de se apropriar minimamente daquilo que a humanidade vem produzindo nas mais diferentes áreas do saber. Assim, quando adentram a escola deve ter início um intenso e contínuo trabalho de valorização da luta que empreendem pela vida, de identificação de significados veiculados e de sentidos formulados, e isso acaba por reconhecer os alunos como sujeitos capazes de aprender e os professores como profissionais capazes de ensinar.

Todos esses condicionantes já apontados e os encaminhamentos citados acabam por reafirmar o que escreve Vygotski (1997): os limites para a não aprendizagem, para a não apropriação dos conteúdos escolares, para o não domínio e o emprego de signos e de instrumentos psicológicos para mediar a relação do aluno com deficiência ou NEE com o mundo são antes impostos pelas relações sociais que pelos aspectos biológicos próprios à condição que apresenta.

Destarte, é preciso que o psicólogo escolar avalie o aluno com deficiência para além da aparência, da imediaticidade da queixa, tendo por parâmetros de análise como a sociedade atual se organiza e quais são as condições concretas da vida desse aluno, o quanto está sendo excluído ou não e a forma, dessa organização societária, que papel ocupa nela, quão consciente é desse papel, o quanto tem de forças para permanecer ou para sair dele. Nota-se que a Psicologia Escolar não se vale de psicoterapia, contudo busca estados de maior consciência junto aos sujeitos com os quais atua. Não é incomum que estudantes atendidos em uma escola historicamente excludente, preconceituosa, fruto de uma sociedade capitalista que perpetua as desigualdades sociais, não tenham a 
mínima ideia disso, aceitando para si e para seu grupo primário responsabilizações que não lhes cabem.

Tem-se, pois, que a psicologia proposta por Vygotski $(1991 ; 1997,2000)$ na década de 1920, tendo como fundamento filosófico e metodológico o materialismo histórico-dialético para a compreensão da constituição e do desenvolvimento do psiquismo humano, inspira o caminho a ser percorrido pelo psicólogo escolar da década de 2020.

Se Vigotski não era um autor inclusivista - posto não haver essa defesa à época, ele lançou fundamentos para a atuação de psicólogos e educadores sob a perspectiva da inclusão - entendida aqui conforme os parâmetros já expostos. Ao defender que pessoas cegas, surdas, surdocegas etc. devessem conviver com aquelas que não se encontravam sob as mesmas condições, põe em debate o conceito de normalidade e evidencia o caráter social da formação do que é propriamente humano nas pessoas.

Com base em seus escritos é possível promover a inclusão do aluno com deficiência, algo que requer o domínio do já criado, apropriando-se, sobretudo, do conhecimento científico com os significados que lhes são atribuídos, e provocando a formação de sentidos. Esse posicionamento em muito diverge do que era defendido na sua época, e ao que se contrapunha: o reconhecimento da educabilidade das pessoas com deficiência, mas com forte tendência ao treinamento e à normalização.

Diante do exposto, ressalta-se que a Psicologia Escolar está às portas da entrada na Educação Especial na perspectiva inclusiva pois precisa acolher as queixas escolares, qualificá-las e responder de modo institucional e individualmente a elas, participando de um trabalho interdisciplinar de valorização do trabalho educativo, fundamentado na ciência e na defesa dos direitos humanos.

\section{Considerações finais}

A Psicologia Histórico-Cultural, como um todo, traz à Educação Especial uma renovação, ao permitir a miragem do devir, do vir a ser de sujeitos que possam se apresentar inicialmente tão à margem do desenvolvimento humano- 
genérico já alcançado. Os escritos de Vygotski em Obras Escogidas Tomo V (1997) sobre os fundamentos teóricos e metodológicos para uma nova defectologia, por sua vez, revelam sua defesa intransigente para a humanização de todas as pessoas. Eles inspiram os profissionais dos dias atuais, ao postular que todos podem aprender, desde que sejam dadas as condições adequadas. Na verdade, isso implica em muitos estudos, na busca por sólida formação teórica. Nessa coletânea de textos, o autor apresenta discussões sobre a convivência entre pessoas com e sem deficiência, ou com defeitos, como se dizia à época, e vários pontos incongruentes a serem superados no campo teórico, de intervenção e de convivência social.

Embora haja uma distância temporal e uma grande diversidade econômica, cultural e política entre a Rússia das décadas de 1920 e 1930 e o Brasil da década de 2020, seus escritos alertam para a necessidade de se pensar as finalidades educacionais. Elas devem contemplar o desenvolvimento integral dos sujeitos, de modo não alienado, levando-os a conhecerem e a governarem a si mesmos e a buscarem por outra sociedade - e isso muito importa à Psicologia Escolar!

\section{Referências}

ANTUNES, M. A. M. Psicologia Escolar e Educacional: história, compromissos e perspectivas. Psicologia Escolar e Educacional, v. 12, p. 469-475, 2008.

https://www.scielo.br/j/pee/a/kgkH3QxCXKNNvxpbgPwL8Sj/?format=pdf\&lang=pt.

ASBAHR, F. S. F.; SOUZA, M. P. R.; BARROCO, S. M. S. Psicologia HistóricoCultural nos Grupos de Pesquisa no Diretório do CNPq no Brasil. Psicologia Teoria e Pesquisa. No prelo.

ALVES, G. L. A produção da escola pública contemporânea. 3.ed.rev. Campinas, SP: Autores Associados, 2005.

BARROCO, S. M. S. Vygotski's theories on Defectology: contributions to the special education of the 21st century. Educação (Porto Alegre), v. 41, n. 3, p. 374384, set.-dez. 2018. DOI: https://orcid.org/0000-0002-4136-8915.

BARROCO, S. M. S.; LEONARDO, N. S. T. A periodização histórico-cultural do desenvolvimento na educação especial: o problema da idade. IN: MARTINS, L. M.; ABRANTES, A. A.; FACCI, M. G. D. Periodização histórico-cultural do desenvolvimento psíquico: do nascimento à velhice. 2. Ed. Campinas: autores Associados, 2020, p. 321-341. 
BRASIL. Constituição da República Federativa do Brasil. Texto constitucional promulgado em 05 de outubro de 1988. Brasília: Senado Federal, 1988.

https://www2.senado.leg.br/bdsf/bitstream/handle/id/518231/CF88_Livro_EC 91_2016.pdf.

BRASIL. Lei 9.394, de 20 de dezembro de 1996. Estabelece as diretrizes e bases da educação nacional. Brasília: Presidência da República, 1996. http://www.planalto.gov.br/ccivil_03/leis/19394.htm.

BRASIL. Lei $n^{o}$ 13.146, de 6 de julho de 2015 Institui a Lei Brasileira de Inclusão da Pessoa com Deficiência (Estatuto da Pessoa com Deficiência). Brasília: Presidência da República, 2015. L13146 (planalto.gov.br).

BRASIL. Lei 13.935, de 11 de dezembro de 2019. Dispõe sobre a prestação de serviços de psicologia e de serviço social nas redes públicas de educação básica, 2019. http://www.planalto.gov.br/ccivil_03/_ato2019-2022/2019/lei/L13935.htm. CONSELHO FEDERAL DE PSICOLOGIA. Referências técnicas para atuação de psicólogas(os) na educação básica. 2. ed. Brasília: CFP, 2019.

FACCI, M. G. D.; TADA, I. N. C. Os laudos e a atuação do psicólogo escolar: explicitação das potencialidades dos alunos. In: RIBEIRO M. J. L. (Org.). Educação Especial e Inclusiva: teoria e prática sobre o atendimento à pessoa com necessidades especiais. Maringá: EDUEM, 2012. p. 117-130.

FACCI, M. G. D; ESPER, M. S. B. Algumas Reflexões Sobre O Sofrimento Do Professor E A Violência Na Escola. In: BARROCO, S. M. S.; SILVA, G. L. R.; TADA, I. N. C. Violência na escola: enfrentamentos à luz da psicologia histórico-cultural. Porto Velho, RO: Coleção Pós-Graduação da UNIR - EDUFRO, 2021, p. 110-135.

https://edufro.unir.br/uploads/08899242/Colecao\%20pos\%20UNIR/2Violencia\%20na\% 20escola.pdf.

INSTITUTO NACIONAL DE ESTUDOS E ESTATISTICAS EDUCACIONAIS ANÍSIO TEIXEIRA. Censo da Educação Básica - Notas Estatísticas. Brasília: INEP, 2020. Censo da Educação Básica 2020 - Notas Estatísticas - Informação da Publicação - INEP.

LEONTIEV, A. O desenvolvimento do psiquismo. Lisboa: Belo Horizonte, 1978.

LEONTIEV, A. N. Uma contribuição à teoria do desenvolvimento da psique infantil. In: VIGOTSKII, L. S.; LURIA, A. R.; LEONTIEV, A. N. Linguagem, desenvolvimento e aprendizagem. São Paulo: Ícone: Editora da Universidade de São Paulo, 20210, p. 59-83. 
MACHADO, A. M. Reinventando a avaliação psicológica. 1996. (doutorado) $240 \mathrm{f}$. Tese (Doutorado em Psicologia Social). Universidade de São Paulo, São Paulo, SP, 1996.

MARCONDES, M. C. M. Recuo da teoria: dilemas na pesquisa em educação. Anais da 24a Reunião Anual da Anped. Caxambu: ANPED, 2001. Associação Nacional de Pós (anped.org.br).

PATTO, M. H. S. A produção do fracasso escolar: histórias de submissão e rebeldia. São Paulo: T. A. Queiroz, 1990.

PATTO, M. H. S. Psicologia e Ideologia. São Paulo: T. A. Queiroz,1987.

PATTO, M. H. S. Introdução à Psicologia Escolar. São Paulo: T. A. Queiroz,1983. ROSSATO, S. P. M.; LEONARDO, N. S. T. Concepções de deficiência intelectual e educação especial: desnaturalizações necessárias. In: RIBEIRO M. J. L. (Org.). Educação Especial e Inclusiva: teoria e prática sobre o atendimento à pessoa com necessidades especiais. Maringá: EDUEM, 2012. p. 73-84.

RUBINSHTEIN, S. L. Objeto, problemas y métodos de la psicología. In: SMIRNOV, A. A.; LEONTIEV, A. N.; RUBINSHTEIN, S. L.; TIEPLOV, B. M. (Org.), Psicología. Cuba: Imprenta Nacional de Cuba, 1962, p. 13-36.

SAVIANI, D. Pedagogia histórico-crítica: primeiras aproximações. 11.ed.rev. Campinas, SP: Autores Associados, 2011.

SAVIANI, D.; GALVÃO, A. C. G. Educação na pandemia: a falácia do "ensino" remoto. Universidade e Sociedade, ANDES-SN n janeiro de 2021, p. 36-49. https://www.andes.org.br/img/midias/0e74d85d3ea4a065b283db72641d4ada_160 9774477.pdf.

SCHLINDWEIN, L. M. A relação teoria e prática na psicologia da educação: implicações na formação do educador. Psicologia Escolar e Educacional, v. 14, n. 2, p. 341-347, 2010. https://doi.org/10.1590/S1413-85572010000200016.

SOUZA, M. P. R. de. A queixa escolar e a formação do psicólogo. Tese (Doutorado em Psicologia). Instituto de Psicologia da Universidade de São Paulo, São Paulo, 1996. $287 \mathrm{f}$.

UNESCO. Declaração mundial sobre educação para todos e plano de ação para satisfazer as necessidades básicas de aprendizagem. Jomtien, Tailândia: UNESCO, 1990.

VIGOTSKII, L. S. 2010. Aprendizagem e desenvolvimento na idade escolar. In: VIGOTSKII, L. S.; LURIA, A. R.; LEONTIEV, A. N. Linguagem, 
desenvolvimento e aprendizagem. São Paulo: Ícone: Editora da Universidade de São Paulo, 20210, p. 103-117.

VIGOTSKI, L. V. A defectologia e o estudo do desenvolvimento e da educação da criança anormal. Educação e Pesquisa, São Paulo, v. 37, n. 4, p. 861-870, dez. 2011. Disponível em: https:/www.scielo.br/j/ep/a/x987G8H9nDCcvTYQWfsn4kN/?lang=pt.

VYGOTSKI, L. S. Obras Escogidas I: problemas teóricos y metodológicos de la Psicologia. Madrid: Visor. 1991.

VYGOTSKI, L. S. Obras Escogidas V: Fundamentos de defectologia. Habana: Editorial Pueblo y Educación. 1997.

VYGOTSKY, L. S.; LURIA, A. R. Estudos sobre a história do comportamento: o macaco, o primitivo e a criança. Porto Alegre: Artes Médicas, 1996. 